\title{
Efficiency and Quality in Higher Education A Dynamic Analysis
}

\author{
Nadia Zrelli Ben Hamida ${ }^{1, *}$ \\ ${ }^{1}$ Higher School of Economic and Commercial Sciences of Tunis, 4, Rue Abou Zakaria El \\ Hafsi - 1089 Montfleury, Tunis \\ *Corresponding author: Tel: 216-99-893-451Ｅ-mail: zrellinadia@yahoo.fr
}

Received: September 12, 2013 Accepted: November 21, 2013 Published: December 10, 2013

doi:10.5296/rae.v5i4.4268 URL: http://dx.doi.org/10.5296/rae.v5i4.4268

\begin{abstract}
During the last decades, these systems passed from elitism to mass given the democratization of the access to higher education. Considering the strong budgetary constraint, higher education institutions are obliged to operate with more efficiency affecting the quality of the offered service. In this work, we propose a dynamic analysis of the efficiency-quality relationship in higher education with the construction of indicators through non-parametric method, Data Envelopment Analysis, and demonstrate a possible dilemma between these characteristics using Malmquist Index.

This technique facilitates the aggregation and weighting of the data used in the construction of the indicator allowing to respect the higher education characteristics of every country. It uses linear programming tools and defines a best practice frontier that serves as a benchmark for estimating the performance of a given set of units. Performance is represented by the distance to the best practice frontier and weights for partial indicators are endogenously calculated in such a way that the distance is minimized for every unit.

For the Quality assessment, we use a variant of DEA model: the radial model without inputs. This approach, traditionally interpreted like a "Helmsman", is supposed to be able to direct all the partial indicators towards their maximum values.

The results show that the countries which severe admission policy are able to manage the quality as well as the quantity of the entrants and, consequently, maintain the quality of the offered service considering the budgetary restriction.
\end{abstract}

Keywords: data envelopment analyses; efficiency; quality; higher education; Malmquist index 


\section{Introduction}

Higher education system (HES) takes a considerable part in the country's economic growth and development. The World Bank defines its main mission as the training of researchers, engineers and technicians able to use their skills for the development, adaptation and the diffusion of innovations.

The two last decades are characterized by HES access democratization. Two main reasons explain this phenomenon. On the one hand, the labor market needs highly qualified labor force. On the other hand, there is a strong demand for HE training which is animated by the hope to find a good employment and thus a better socio-economic situation. Given these circumstances, higher education institutions (HEI) are constrained to release the criteria of admissions.

With this democratization, public authorities find more difficulties to guarantee the necessary financial resources obliging HEI to operate with more efficiency. Thus, with budgetary restriction combined to a phenomenon of "mass" higher education, the planners confront the need to maintain the quality of the offered service.

This study tries to answer the following question: could the passage from elitist to mass higher education, with more efficiency, affect the quality of tertiary training? The first section will present a theoretical approach of higher education efficiency and quality. The second section will explain the estimation method used in the construction of indicators. The third section will highlight the obtained results and their interpretations.

\section{Higher Education Efficiency and Quality: Theoretical Approach}

The current conjuncture of the mass HES explains the abundance of work relating to the topic of efficiency whereas the quality concept remains evasive and encircled.

\subsection{Internal efficiency in higher education system}

According to Schwartz (1969), the allocation of new resources or additional resources seems to depend more and more on the obtained results. The assessment of results according to the mobilized resources falls under the evaluation of efficiency. Lê Than Khôi (1967] advances that, "the total productivity of the factors or the used resources makes it possible to determine the degree of efficiency of an economy or its various branches". Efficiency is based on the relationship between the observed effects and the mobilized resources. It expresses "the relationship between what is carried out and the implemented means".

Internal quantitative efficiency stresses the quantitative nature of educational systems results expressed according to the mobilized financial resources. This indicator is generally evaluated through the relationship between the number of graduates and academic and non-academic staff salaries or by the relationship between enrollments and teachers' salaries.

With minimization costs orientation, the study of internal quantitative efficiency makes possible the assessment of the financial resources necessary to carry out a given output level. 
The first step in the efficiency determination is the identification of a standard level from which we derive the estimation. This consists in identifying the institutions that minimize the use of the inputs to carry out a given level of output. This sample of institutions forms an envelope or a border from which any deviation is regarded as inefficient.

\subsection{Higher education quality}

The interest carried to the quality of higher education is explained by the following phenomena:

- General tendency of improvement of the quality of the public services;

- Mass higher education;

- Competition compared to the financial resources;

- Efficiency-quality dilemma.

In Lomas (2002) it is reported that Ritzer (1996) introduced Mcdonalisation term to highlight the HES loss of "prestige" due to their mass. Indeed HEI are not much different from the institutions offering other services. The consumer expects the same standards and quality from higher education as what he expects from buying a Hamburger or carrying out a banking transaction. This argument is an instrument of warning statements compared to the Mcdonalisation of higher education. Thus, it highlights the importance of quality improvement, which should be a priority among the objectives of the educational policy.

Following this renewed interest to the higher education quality, a polemic concerning its definition appeared. Indeed, until now there is no common definition of this concept. "Defining higher education quality is one of the most difficult spots to be made". Pirsig (1974) advances that "the concept is evasive" and that there is no criteria or standards to measure it.

According to the final report of the commission on the quality of higher education, presented to the higher education world conference UNESCO (1998), "quality is a complex concept, dynamic, with multiple facets, and which is based on often definite historical data by what is lacking rather than by its contents". The report presents also the quality of higher education like "the reflection of socioeconomic, cultural and political designs at the regional, national and world level".

Martin and Stella (2007) present two reasons explaining the encountered difficulties when it is a question of defining higher education quality. On one hand, there is no consensus on the precise objectives of higher education (the production of qualified labor and the training of future researchers). On the other hand higher education, like any other type of teaching, is a complex and multidimensional process based on the existing relationship between and among teachers and students. The interactions between the resources and the outputs as well as the real determinants of the results are difficult to identify. With HES which support integration and heterogeneous student's population, there is an increasing diversification and tertiary education training demand. Thus, a good definition of quality can be appropriate for a certain type of course or establishment, but it can be completely inappropriate for others. 


\section{Higher Education Efficiency and Quality Assessment: Data Envelopment Analysis}

The DEA is a deterministic and non-parametric method. It circumvents the problem of a functional form relating the various variables and determining an empirical border according to the observed data. The mathematical basis of DEA method returns to Farrel (1957) and Debreu (1951). The main objective of their work is to specify a linear programming able to empirically identify the economic aspects of the production phenomenon. The application of model DEA permits the construction of internal efficiency and quality indicators of HES.

Models presentation

Like any public sector, mainly financed by public funds, higher education is subjected to strong budgetary constraints. The DEA model used for efficiency measure is the inputs oriented model (Figure 1). This optic enables us to measure the possible used inputs reduction with maintaining the same output level. In addition, the obtained efficiency scores allow the detection of the most efficient HES, of sources of wasting financial resources, and of scale efficiency. For the quality assessment, we propose a higher education quality composite indicator (QCI). We use an alternative of DEA model: a radial model without inputs (Lovell and Pastor (2002)). According to Koopmans (1951) and Lovell and Pastor (2002), this approach is traditionally interpreted like a "helmsman" able to direct all the partial indicators towards their maximum values.

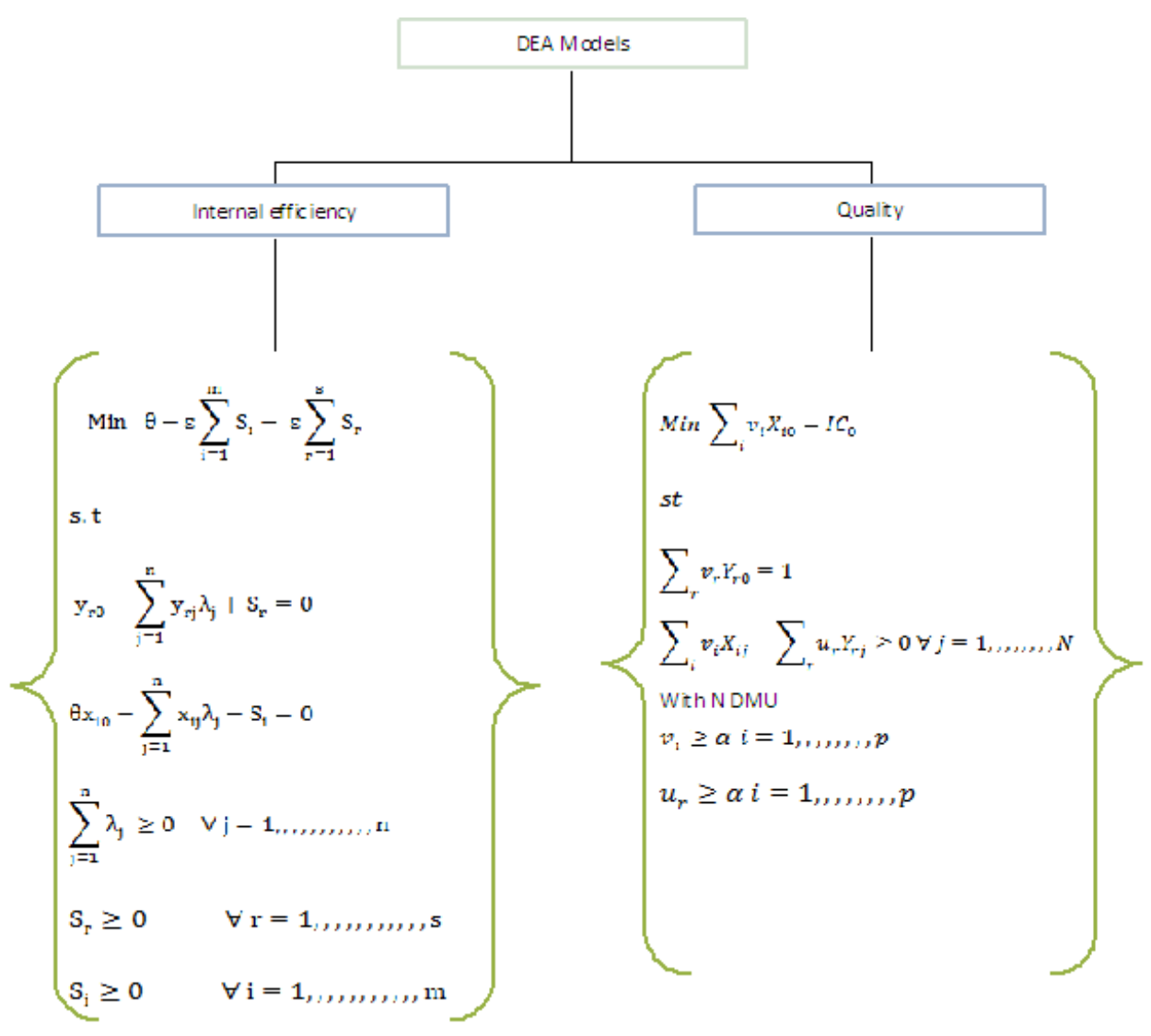

Figure 1: DEA models for efficiency and quality assessment 
The DEA dual efficiency model supposes that the indicators of efficiency are placed on a convex curve. We choose a DEA radial input oriented model. We can determine the possible reduction of the inputs while producing the same quantity of output and identify the scale efficiency. The indicators obtained are between 0 and 100 (expressed as a percentage). More the score is close to 100 more the studied DMU is efficient. Dual variables $\lambda_{1}, \ldots, \ldots,, \lambda_{n}$ present the same interpretation than the Lagrangian multiplier and are between 0 and 1. More the value of $\lambda$ being near to 1 , more the DMU is relatively efficient according to others studied DMU.

To realize the nearest output $\mathrm{Y}_{\mathrm{r} 0}$ to $\sum_{j=1}^{n} y_{r j} \lambda_{j}$, the DMU must use the minimum of inputs equivalent to $\sum_{j=1}^{n} x_{r j} \lambda_{j}$. This implies that $\theta^{*}$ is the least input proportion used by the DMU in the production process: it represents the efficiency score. If $\theta=0.6$ thus $40 \%$ of resources are wasted.

The quality DEA model is a Radial model without inputs. To calculate the QCI it is necessary to consider an oriented output DEA model with only one input, a dummy equal to the unit, for all the studied DMU. The objective is to maximize the QCI given the constraint of the partial indicators.

$V_{r j}=\frac{u_{r} Y_{r j}}{\sum_{r=1}^{q} u_{r} Y_{r j}}$ Represent the contribution of each partial indicator in the construction of the QCI. Various restrictions are integrated through the following equations:

Restriction A: $\mathrm{V}_{\mathrm{rj}} \geq 0.0001$ and $\mathrm{u}_{1} \geq 0.0001$ : each partial indicator must take part in the construction of the QCI.

Restriction B: $\mathrm{V}_{1}+\mathrm{V}_{2}+\mathrm{V}_{3+} \mathrm{V}_{4=1}$ : each partial indicator contribution is defined by its weighting which is obtained, for each studied year, through a principal components analysis (PCA).

QCI and efficiency scores are calculated by EMS 3.1 software. Weightings are obtained by the PCA with SPSS 13.0. Estimations are based on aggregated national data. The choice of the data is conditioned by their availability. It also allows us to avoid two main issues: an aggregation problem and the HES institutional differences from one country to another. Indeed the aggregation procedure requires specific assumptions so that quality and efficiency measurements, obtained at the country aggregate level, reflect exactly an average measure for the whole higher education establishments.

For the DEA efficiency model (Figure 2), input variable is the public expenditure per student expressed as a percentage of the per capita GDP (PubExp). For the teaching activity, outputs are graduates (TG) (ISCED 5A, 5B and 6) and not-graduate student's population (TNG). Scientific publications ( TSP) represent the research output. 
A composite indicator, obtained through the combination of the following partial indicators, evaluates the offered teaching quality:

- The supervision rate (SR) guarantees a better comprehension of the provided lesson. Supervision rate is defined as being the reverse of students per teacher ratio. This ratio is the relationship between students of a given teaching level, in full time equivalent, and the number of teachers of the same level and the same type of establishment, in full-time equivalent.

- School life expectancy (ISCED 5 and 6) (TSLE): "the sum of age-specific enrolment rates expressed as a percentage divided by 100, for the specified education levels. To compensate for the lack of reliable data by age for tertiary education, the gross enrolment ratio for tertiary education is multiplied by 5 , divided by 100 , and used as a proxy for age-specific enrolment rates" (Global Education Digest UNESCO).

- The attractivity and the quality of the offered tertiary training at the international level is introduced through the inbound mobility rate (FS).

- The percentage of graduates (PG) compared to the total student enrollments considers the system capacity to produce the graduates. By disaggregating the ISCED graduates categories, we could study their correlation with school life expectancy.

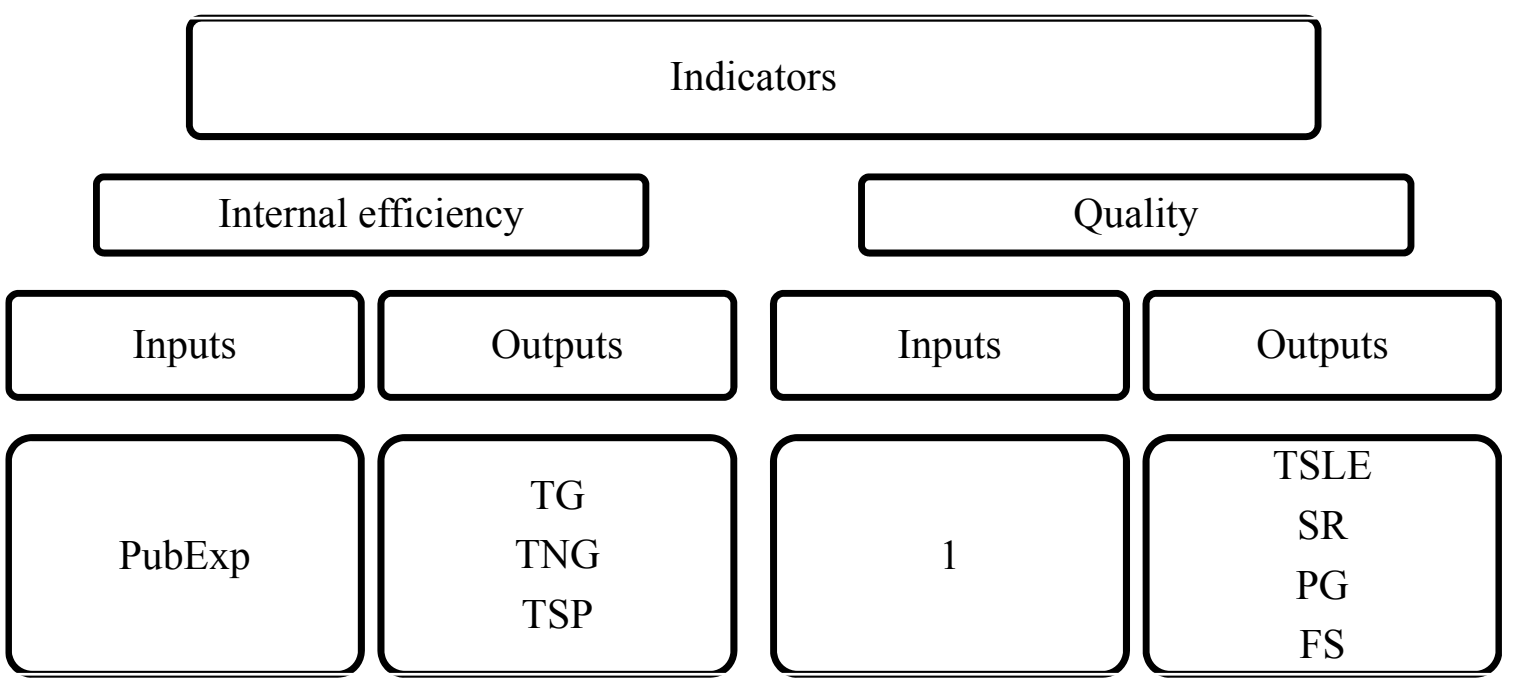

Figure 2: Efficient and quality partial indicators

The data cover the period 2001-2007. Those relating to the teaching activity are obtained from Edstat databases (the World Bank), the Global Education Digest (UNESCO) and the "Education at a glance" OECD. The number of scientific publications is obtained from SCImago Journal and country Rank site which is relevant to the Scopus database (www.scimagojr.com).

The study include 16 countries: Morocco, Tunisia, the Czech Republic, Hungary, Slovakia, Finland, France, Greece, Ireland, the Netherlands, Norway Spain, the United Kingdom, Japan, Italy and Sweden. 


\section{Results and Interpretation}

\subsection{Higher education efficiency}

The various efficiency scores obtained are presented in table 1:

Table 1: Higher education efficiency scores (in percentage)

\begin{tabular}{lccccccc}
\hline & 2001 & 2002 & 2003 & 2004 & 2005 & 2006 & 2007 \\
\hline Morocco & 18,49 & 19,69 & 25,15 & 27,93 & 23,51 & 25,60 & 26,83 \\
Tunisia & 24,73 & 27,69 & 29,11 & 30,81 & 34,41 & 35,32 & 35,90 \\
Czech Republic & 55,97 & 56,03 & 59,71 & 69,13 & 70,60 & 51,13 & 64,21 \\
Hungary & 53,75 & 54,42 & 63,22 & 85,49 & 80,47 & 80,10 & 82,13 \\
Slovakia & 56,81 & 56,58 & 69,07 & 64,78 & 80,02 & 77,88 & 100 \\
Finland & 47,16 & 46,99 & 54,09 & 57,68 & 55,88 & 57,11 & 61,77 \\
France & 60,81 & 60,19 & 58,82 & 61,28 & 57,97 & 57,22 & 57,31 \\
Greece & 71,24 & 72,21 & 91,46 & 84,77 & 76,71 & 88,67 & 91,20 \\
Ireland & 61,59 & 65,73 & 82,80 & 87,36 & 77,93 & 73,07 & 74,70 \\
Netherlands, & 40,31 & 41,57 & 45,48 & 47,86 & 45,33 & 45,03 & 48,99 \\
Norway & 39,91 & 36,20 & 40,37 & 40,44 & 39,14 & 42,50 & 41,42 \\
Spain & 81,22 & 79,39 & 87,73 & 92,18 & 84,73 & 81,41 & 78,98 \\
United Kingdom & 76,74 & 61,69 & 72,94 & 100 & 100 & 100 & 100 \\
Japan & 100 & 100 & 100 & 100 & 100 & 100 & 100 \\
Italy & 69,73 & 65,93 & 84,78 & 91,76 & 86,57 & 81,68 & 89,88 \\
Sweden & 35,11 & 35,41 & 43,68 & 49,28 & 47,98 & 49,07 & 51,31 \\
\hline
\end{tabular}

The countries with lowest efficiency levels correspond to the highest unit costs of the sample and vice versa, confirming the opposite relation between the unit costs and the level of efficiency suggested by Bayanet and Debande (2001) (Figure 3).

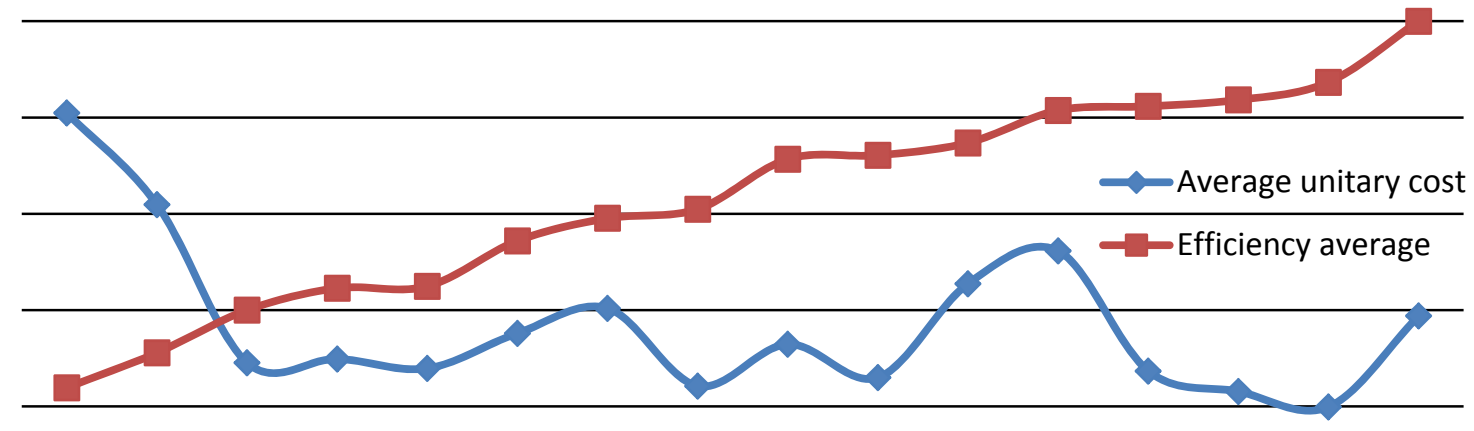

Figure 3: Efficiency- Higher education unit cost relationship

The comparison of efficiency indicators, with non-increasing economies of scales (NES), to those obtained under the assumption of variable efficiency scales (VES) identifies the return 
to scale nature. If a given HES obtains the same efficiency scores under NES and VES, it operates with decreasing return to scales. With different scores, return to scale is increasing. The return to scale is constant if the HES operate on the efficiency border. According to the found results, all the studied countries operate with increasing return to scales, except Japan and the United Kingdom presenting a constant return to scale reaching their optimal size. These results confirm that the unanimity of the HES realizes scale economies.

Table 2: Weights of efficiency determinants for 2001

\begin{tabular}{lcc}
\hline & \multicolumn{2}{c}{ Efficiency weights } \\
\cline { 2 - 3 } Morocco & 0,8744 & 0,1256 \\
Tunisia & 0,6311 & 0,369 \\
Czech Republic & 0,6081 & 0,3919 \\
Hungary & 0,9172 & 0,0828 \\
Slovakia & 0,0726 & 0,9274 \\
Finland & 0,1504 & 0,8496 \\
France & 0,9072 & 0,0928 \\
Greece & 0,0021 & 0,9979 \\
Ireland & 0,1871 & 0,8129 \\
Netherlands & 0,3583 & 0,6417 \\
Norway & 0,9532 & 0,0468 \\
Spain & 0,9999 & 0,0001 \\
United Kingdom & 0,9655 & 0,0345 \\
Japan & 0,0359 & 0,9641 \\
Italy & 0,9817 & 0,0183 \\
Sweden & 0,7031 & 0,2969 \\
\hline
\end{tabular}

The DEA method enables us to determine each higher education activity efficiency contribution through its weighting (Table 2). In 2001, for the Tunisian HES, 36.89\% of efficiency is due to the research activity and $63.10 \%$ to the teaching activity. In Morocco, the teaching activity explains the efficiency with $87.44 \%$ whereas research activity explains it with only $12.55 \%$. Certain countries present an efficiency level lower than $50 \%$, but which is mainly explained by the research activity such as Sweden, Norway, The Netherlands and Finland. The United Kingdom presents an efficiency score of $76.74 \%$ explained at $99.79 \%$ by its research activity. The most efficient HES are of Spain and Japan with respectively $82.11 \%$ $100 \%$ efficiency scores which are explained by the teaching activity with respective weightings of 0.9817 and 0.9998 . 
Table 3: Dynamic analysis of efficiency in higher education

\begin{tabular}{lccc}
\hline & & \multicolumn{2}{c}{ Malmquist index decomposition } \\
& Malmquist Index & $\begin{array}{c}\text { Techical efficiency } \\
\text { change }\end{array}$ & $\begin{array}{c}\text { Technological } \\
\text { change }\end{array}$ \\
\hline Morocco & 0,9423 & 0,7908 & 1,1227 \\
Tunisia & 0,8804 & 0,691 & 1,1217 \\
Czech Republic & 1,059 & 0,9994 & 1,1222 \\
Hungary & 0,8927 & 0,71 & 1,1223 \\
Slovakia & 0,8451 & 0,637 & 1,1212 \\
Finland & 0,9627 & 0,8252 & 1,123 \\
France & 1,167 & 1,1944 & 1,1402 \\
Greece & 0,9945 & 0,8795 & 1,1246 \\
Ireland & 0,9782 & 0,8534 & 1,1213 \\
Netherlands & 1,0002 & 0,887 & 1,1278 \\
Norway & 1,1612 & 1,2018 & 1,1221 \\
Spain & 1,1793 & 1,2214 & 1,1387 \\
United Kingdom & 0,9343 & 0,7587 & 1,1506 \\
Japan & 1 & 1 & 1 \\
Italy & 0,9728 & 0,8311 & 1,1388 \\
Sweden & 0,9324 & 0,7719 & 1,12617 \\
\hline
\end{tabular}

The efficiency dynamic evolution is studied throught Malmquist index productivity. This index measures the variation of the productivity between two observations by calculating the ratio of the distances from each one compared to a technology. If the obtained index is lower than the unit then there is an efficiency improvement (Table 3).

The obtained Malmquist index shows that for the considered periods, 10 among the 16 studied countries present an efficiency improvement in their financial resources use. The Malmquist index decomposition defines the productivity change by considering the movement along the efficiency border, i.e. the change of technology production, and the changing of efficiency border. In our case, we deduce that the efficiency improvement is mainly due to the cost control and not to the enhancement of the way of financial resources spending.

\subsection{Composit indicator of the quality of higher education}

Table 4: Composit indicator of the quality of higher education

\begin{tabular}{lccccccc}
\hline & 2001 & 2002 & 2003 & 2004 & 2005 & 2006 & 2007 \\
\hline Morocco & 0,5992 & 0,5599 & 0,493 & 0,512 & 0,5749 & 0,5707 & 0,794 \\
Tunisia & 0,5705 & 0,5358 & 0,5354 & 0,5435 & 0,5981 & 0,6355 & 0,6511 \\
Czech Republic & 0,7366 & 0,6993 & 0,6815 & 0,6858 & 0,6967 & 0,7704 & 0,805 \\
Hungary & 0,8091 & 0,8044 & 0,7977 & 0,7869 & 0,8192 & 0,8296 & 0,8084 \\
Slovakia & 0,9439 & 0,9584 & 0,9469 & 0,9497 & 0,8824 & 0,8411 & 0,8324 \\
Finland & 1 & 1 & 1 & 1 & 1 & 1 & 1 \\
\hline
\end{tabular}




\section{Macrothink}

\begin{tabular}{lccccccc}
\hline France & 0,9444 & 1 & 1 & 1 & 1 & 0,981 & 0,9869 \\
Greece & 0,6918 & 0,7749 & 0,8065 & 0,8741 & 0,9424 & 0,977 & 0,9052 \\
Ireland & 1 & 0,9936 & 1 & 1 & 1 & 1 & 1 \\
Netherlands & 0,8602 & 0,8403 & 0,8219 & 0,8179 & 0,841 & 0,8673 & 0,8753 \\
Norway & 0,9582 & 0,9083 & 0,9299 & 0,9574 & 0,9742 & 0,9927 & 1 \\
Spain & 0,8655 & 0,8631 & 0,8825 & 0,8563 & 0,8969 & 0,877 & 0,8839 \\
United Kingdom & 1 & 1 & 1 & 1 & 1 & 1 & 1 \\
Japan & 1 & 1 & 1 & 1 & 1 & 1 & 1 \\
Italy & 0,6939 & 0,7016 & 0,7312 & 0,7731 & 0,8144 & 0,8421 & 0,8433 \\
Sweden & 1 & 1 & 1 & 1 & 1 & 1 & 1 \\
\hline
\end{tabular}

All things being equal, the 16 studied countries present a light average higher education quality improvement (Table 4). The average QCI increased by 0.8545 in 2001 to 0.8990 in 2007. This statistical analysis enables us to deduce that over the 7-year-studied period, Tunisia and Morocco present an average QCI of 0.58 which is the weakest of the sample. On the other hand, Finland, RU, Japan and Sweden have over all the period the best quality of the sample.

Table 5: Partial indicators weights explaining higher education quality

\begin{tabular}{ccccc}
\hline & TSLE & FS & SR & PG \\
\hline 2001 & 0.52943 & 0.25582 & 0.14123 & 0.0735 \\
2002 & 0.47835 & 0.23629 & 0.17831 & 0.1070 \\
2003 & 0.49981 & 0.22044 & 0.17212 & 0.1076 \\
2004 & 0.44694 & 0.26315 & 0.19021 & 0.0997 \\
2005 & 0.40339 & 0.27294 & 0.24078 & 0.0828 \\
2006 & 0.39104 & 0.27276 & 0.24800 & 0.0882 \\
2007 & 0.35620 & 0.33090 & 0.24951 & 0.0063 \\
\hline
\end{tabular}

The weights obtained with PCA are presented in the table 5. The weightings analysis (Table 4) shows that school life expectancy and the percentage of graduates explain less and less the quality, leaving the place to the international attractivity and the ratio students teaching staff.

The inbound mobility rate expresses opportunity to reach a better higher education quality given the origin country. In the considered sample, France and UK foreign students represent in 2007 respectively $10.03 \%$ and $12.65 \%$ of the total student's population. For Tunisia and Morocco, it is only respectively $0.89 \%$ and $1.59 \%$ of the total enrollment.

The percentage of graduates compared to the total student enrollments express the graduate's production capacity of HES. Countries with best quality present a strong capacity to produce which reflects low levels of repeaters and dropout rates. France and Ireland are located on the best quality envelope. They present an initially higher graduate's production capacity with a net increase over the period 2001-2007, with a respective proportion of $25.40 \%$ and $27.50 \%$ of students getting their diplomas at the end of the academic year 2001, increasing to $28.58 \%$ and $31 \%$ in 2007 . For Tunisia and Morocco this partial indicator explains to a low extent the 
quality with respective rates of $11.83 \%$ and $14.12 \%$ in 2001 to reach $17.96 \%$ and $23.88 \%$ in 2007.

A low students teaching staff ratio guarantees a better comprehension of the lesson and explains partially the low levels of repeaters and dropout rates. The best quality presented by the countries with students teaching staff ratio presents an important increase from 2001 to 2007. In Sweden, it passed from 4 teachers by 100 students in 2001 to 11 in 2007 . In the case of Japan, the students teaching staff ratio reached a teacher for 10 students, which mainly explains the quality of higher education.

Countries presenting less quality than Sweden and Japan are characterized by a fall of students teaching staff ratio. For example, Italy had 9 teachers by 100 students in 2001 which fall to 5 teachers by 100 students in 2007. Slovakia and Hungary present the same tendency where students teaching staff ratio passed respectively from 8 and 9 in 2001 to 6 and 7 in 2007. Tunisia and Morocco present a stagnation of this partial indicator fixed at 5 over all the period. Greece presents only 4 teachers for 100 students.

We can also explain composite indicators with correspondence between school life expectancy and the dominating type of formation (ISCED 5A, 5B and 6). School life expectancy explains more quality. Finland presents the most important school life expectancy, which increased 4 years and 2 months in 2001 to 4 years and 7 months in 2007. It is closely associated to the ISCED 5A enrollment increase (90.13\% in $2001,92.90 \%$ in 2007). This result is partially explained by the "Numerus Clausus" application in all fields of study. Admission is based on an entrance examination or on school certificates.

The higher education systems of Ireland, UK and Japan are characterized by a strong participation in the ISCED 5B with more than the quarter of the student's population. The higher education school life expectancy in these countries corresponds to the duration of this formation with an average of 3years. On the other hand, the access to advanced formation is conditioned by admission's criteria. In Ireland, the selection is realized through the "National Entrance Examination" and the "Numerus clausus" application, thus $60 \%$ of places are allocated according to merit/locality factors. In Greece, higher education access is restricted and dependent on candidates' grades and preferences. These countries present consequently a life expectancy improvement that increased from 2 years and 10 months in 2001 to more than 4 years in 2007. The ISCED 5A and the ISCED5B enrollments rates are relatively stable with respective averages of $62.61 \%$ and $34.24 \%$ over the period $2001-2007$. The participation in the advanced research formations ISCED6 has increases from $2.33 \%$ to $3.6 \%$.

The countries with lowest QCI are distinguished by discordance between school life expectancy and the dominating training type. The Czech Republic and Hungary present over the 2001-2007 period a respective average school life expectance of 2 years and 2 years and 9 months. The proportion of ISCED 5A students are respectively of $83.19 \%$ and $93 \%$. Similarly, Tunisia and Morocco present a respective average life expectance of one year and 5 months and 7 months and respectively $72 \%$ and $80 \%$ of the ISCED5A student's enrollments'. These HES are also characterized by the Numerus Clausus non-application. The Czech Republic and Hungary policy admission is limited to the HE institutions reception capacity and so 
according to places availability. Tunisia and Morocco apply restrictions only on certain fields of study to obtain diplomas like Medical doctors, pharmacists and engineers.

The higher education quality depends on the control of the entrance quality through the admission policy and the adopted educational policies. According to the various characteristics of the studied HES, the adoption of a Numerus Clausus as an admission policy guarantees a better mass management and an important rate of success. The direct consequence is a better training quality reflected by the fall of repeater and dropout rates, and school life expectancy improvement.

\subsection{With mass higher education is there a dilemma between efficiency and quality?}

To identify the efficiency-quality dilemma we compare efficiency and quality Malmquist index. We calculate with DEA method the necessary partial indicators increase to guarantee the best sample quality (Table 6). If the obtained Malmquist index is higher than the unit so the partial quality indicators did not increase enough to reach the better training quality of the sample.

Table 6: The necessary partial quality indicators increase to reach the best quality of the sample (in pourcentage)

\begin{tabular}{lccccccc}
\hline & 2001 & 2002 & 2003 & 2004 & 2005 & 2006 & 2007 \\
\hline Morocco & 166,90 & 178,59 & 202,85 & 195,29 & 173,94 & 175,23 & 125,94 \\
Tunisia & 175,28 & 186,63 & 186,78 & 183,98 & 167,21 & 157,35 & 153,58 \\
Czech Republic & 135,76 & 143,01 & 146,73 & 145,81 & 143,54 & 129,80 & 124,22 \\
Hungary & 123,59 & 124,32 & 125,36 & 127,08 & 122,07 & 120,54 & 123,70 \\
Slovakia & 105,94 & 104,34 & 105,60 & 105,30 & 113,33 & 118,89 & 120,14 \\
Finland & 100 & 100 & 100 & 100 & 100 & 100 & 100 \\
France & 105,89 & 100 & 100 & 100 & 100 & 101,94 & 101,33 \\
Greece & 144,55 & 129,05 & 124,00 & 114,41 & 106,11 & 102,36 & 110,47 \\
Ireland & 100 & 100,65 & 100 & 100 & 100 & 100 & 100 \\
Netherlands, & 116,25 & 119,01 & 121,67 & 122,26 & 118,91 & 115,30 & 114,25 \\
Norway & 104,36 & 110,10 & 107,54 & 104,45 & 102,64 & 100,73 & 100 \\
Spain & 115,53 & 115,86 & 113,31 & 116,79 & 111,50 & 114,03 & 113,14 \\
United Kingdom & 100 & 100 & 100 & 100 & 100 & 100 & 100 \\
Japan & 100 & 100 & 100 & 100 & 100 & 100 & 100 \\
Italy & 144,12 & 142,53 & 136,77 & 129,34 & 122,79 & 118,75 & 118,58 \\
Sweden & 100 & 100 & 100 & 100 & 100 & 100 & 100 \\
\hline
\end{tabular}

According to these results, Tunisia realizes a relative quality improvement. The necessary increase of the partial indicators to the quality improvement was reduced from $75.28 \%$ in 2001 to $53.58 \%$ in 2007 . However, it must make the most effort to reach the quality of Japan or Sweden. Morocco, the Czech Republic and Hungary must, on average, increase partial indicators of $24 \%$.

Are the HES constrained to operate with less efficiency to guarantee better quality? 


\section{Macrothink}

Table 7: Efficiency-quality dilemma through Malmquist index

\begin{tabular}{llcc}
\hline & & \multicolumn{2}{c}{ Mamlquist index } \\
\hline Group & & Quality & Efficiency \\
\hline \multirow{4}{*}{ Greece } & 1,3025 & 0,8762 \\
& Morocco & 1,1512 & 0,9320 \\
& Italy & 1,1024 & 0,9524 \\
Tunisia & 1,0683 & 0,9675 \\
& Czech Republic & 1,0454 & 0,9780 \\
& France & 1,0223 & 0,9891 \\
& Norway & 1,0216 & 0,9894 \\
& Spain & 1,0105 & 0,9948 \\
& Netherlands & 1,0087 & 0,9957 \\
$\boldsymbol{0}$ & Finland & 1,0000 & 1,0000 \\
& Ireland & 1,0000 & 1,0000 \\
& United Kingdom & 1,0000 & 1,0000 \\
& Japan & 1,0000 & 1,0000 \\
& Sweden & 1,0000 & 1,0000 \\
& Hungary & $\mathbf{0 , 9 9 9 6}$ & $\mathbf{1 , 0 0 0 2}$ \\
& Slovakia & $\mathbf{0 , 9 3 9 0}$ & $\mathbf{1 , 0 3 1 9}$ \\
\hline
\end{tabular}

According to Malmquist index (Table 7), we distinguish three groups of countries. Group B-Finland; Ireland, KU, Japan and Sweden- which maintain balance between efficiency and quality. Group C, with only two countries -Hungary and Slovakia- guarantee quality at the price of efficiency. For the 9 remaining countries- group A- partial quality indicators did not increase enough to ensure best quality but, according to the efficiency Malmquist index, they realize a better financial resources use.

The assessment of the higher education quality is mainly carried out through a descriptive analysis of the rare data presented in different reports of international organisations such as the World Bank or the UNESCO. This research is the first one trying to provide a measurement of the quality of higher education using the DEA approach and, consequently, the analysis of the correlation between quality and efficiency at the macroeconomic and dynamic perspectives. We can consequently conclude that higher education quality is the first democratization victim. Adopting a restrictive admission policy makes possible the student flow management and quality control. These admission policies are exclusively practiced by elitist institutions that enjoy of a good reputation for the training quality and the diplomas credibility on the labor market. The mass HEI are characterized by a laxest admission policy obliging them to operate with more efficiency and the quality loss. The obtained Malmquist index proof that to guarantee better quality, mass higher education systems are constrained to give up efficiency objectives. 


\section{Conclusion}

The HES evaluation became essential. Given the access democratization to this advanced training, several authors announce the risk of prestige loss and Mcdonalisation. Through a non-parametric estimation, this study enabled us to highlight the risk of qualitative degradation of the tertiary training if this mass transition is not financially supported. The efficiency-quality dilemma is effectively checked through composite indicators construction and their dynamic analysis thanks to the Malmquist index.

It is clear that, according to the characteristics of each HES, certain countries could maintain the quality of their formation thanks to the application of a Numerus Clausus. Indeed a severe admission policy makes it possible to manage flows of entering to HES quantitatively and qualitatively.

Using higher education as an economic and social development instrument is obvious, but democratization without financial supports can lead to an opposite purpose through the questioning of the formation and the credibility of the diplomas on the labor market.

\section{References}

Bayanet, B., \& Debande, O. (1999). Performance des activités d'éducation et de recherche des systèmes d'enseignement supérieur de l'OCDE. Annales Of public and cooperative economics, 70(4), 659-686. http://dx.doi.org/10.1111/1467-8292.00128

Debreu, G. (1951). The coefficient of resource utilization. Journal of the Econometric Society, 273-292.

Farrell, M. J. (1957). The measurement of productive efficiency. Journal of the Royal Statistical Society Series A, 120(3), 253-290. http://dx.doi.org/10.2307/2343100

Koopmans, C. (1951). Activity analyses of production and allocation. Chapman and Hall publishing London 1951.

Lê Than Khoî. (1967). L'industrie de l'enseignement. Edition de Miniuit, Paris.

Lomas, L. (2002). Does the development of mass education necessarily mean the end of quality. The sixth QHE Seminar.

Lovell, K., \& Pastor, J. (2002). Radial DEA models without inputs or without outputs. European journal of operational research, 118(1), 45-51.

Martin, M., \& Stella, A. (2007). Assurance qualité externe dans l'enseignement supérieur : les options Institut internationale de planification de l'éducation. UNESCO.

Pirsig, R. (1974). Zen and the Art of Motorcycle Maintenance- An inquiry into values Boadly. Head Publishing, UK.

Schwartz, H. H. (1969). Concerning the contention that efficiency in the allocation of resources really doesn't matter very much after all. Economic Development and Cultural 
Change, 18(1), 44-50. http://dx.doi.org/10.1086/450403

Ritzer, G. (1996). McUniversity in the Post-modern consumer society. Quality in Higher Education, 2(3), 185-199. http://dx.doi.org/10.1080/1353832960020302

UNESCO, (1998). Déclaration mondiale sur l'enseignement supérieur pour le XXIe siècle : Vision et actions. UNESCO.

\section{Glossary}

DEA: Data Envelopment Analysis.

DMU: Decision Making Unit.

FS: Foreign students as a $\%$ of all tertiary.

GDP: Gross Domestic Product

HEI: Higher Education Institustion.

HES: Higher Education System.

ISCED: International Standard Classification of Education

ISCED 5B: Tertiary-type B programmes focus on practical, technical or occupational skills for direct entry into the labour market.

ISCED 5A: programmes theory-based and designed to provide sufficient qualifications for entry to advanced research programmes and professions with high skill requirements.

ISCED 6: Tertiary programmes leading to the award of an advanced research qualification.

NES: Non-increasing Economies of Scales

PCA: Principal Component Analysis

PG: Percentage of graduates compared to the total student staff.

PubExp: Public expenditure per student as a \% of GDP per capita Tertiary education.

QCI: Quality Composit Indicator.

SR: Reverse of ratio of student to teaching staff in tertiary education as supervision rate.

TG: Total graduates.

TNG: Total non graduates students.

TSLE: Tertairy school life expectancy (ISCED 5and 6).

TSP: Total scientific publications.

VES: Variable Economies of Scale.

\section{Copyright Disclaimer}

Copyright reserved by the author(s).

This article is an open-access article distributed under the terms and conditions of the Creative Commons Attribution license (http://creativecommons.org/licenses/by/3.0/). 